
375-380.

\title{
Crescimento e acúmulo de nutrientes pela abóbora híbrida tipo Tetsukabuto
}

\author{
Sanzio Mollica Vidigal'1; Dilermando Dourado Pacheco²; Cláudio Egon Facion ${ }^{3}$ \\ ${ }^{1}$ EPAMIG-CTZM, Vila Gianetti, 46/47, Campus UFV, 36571-000Viçosa-MG; Bolsista BIPDT/FAPEMIG, ${ }^{2}$ EPAMIG-CTNM, C. Postal \\ 12, 39440-000 Nova Porteirinha-MG; 3EPAMIG-CTCO, C. Postal 295, 35701-970 Sete Lagoas-MG; sanziomv@epamig.br
}

\section{RESUMO}

Um experimento foi conduzido em Jaíba (MG) para avaliar o crescimento e o acúmulo de nutrientes pela abóbora híbrida, cv. Suprema. As amostragens de plantas foram realizadas aos 28; 42; 56; 70; 84 e 98 dias após a semeadura (DAS) para determinação da matéria seca das folhas, caule, flor, fruto e raiz. A planta teve lento crescimento até 56 DAS e a partir daí o crescimento intensificou-se até o final do ciclo. A produção total de matéria seca máxima ocorreu aos 89 DAS, atingindo 1.657,92 g planta $^{-1}$. Os frutos acumularam mais matéria seca que outros órgãos da planta. A taxa de crescimento absoluto da planta e dos frutos foram 124,25 e 172,75 g planta $^{-1}$ dia $^{-1}$, aos 74 e 79 dias, respectivamente. A absorção de nutrientes seguiu o padrão da curva de acúmulo de matéria seca pelas plantas. O acúmulo de nutrientes foi reduzido nos primeiros 42 DAS, intensificando-se a partir daí, acumulando continuamente até o final do ciclo para $\mathrm{N}, \mathrm{S}, \mathrm{Mg}$ e os micronutrientes. $\mathrm{O} \mathrm{K}$ foi o nutriente mais absorvido pela planta, seguido do $\mathrm{Ne} \mathrm{Ca}$. A ordem de macronutrientes acumulados foi $\mathrm{K}>\mathrm{N}>\mathrm{Ca}>\mathrm{P}>\mathrm{Mg}>\mathrm{S}$ e de micronutrientes foi $\mathrm{Fe}>\mathrm{Mn}>\mathrm{Zn}>\mathrm{Cu}$. Na colheita, aos 98 DAS, 69\% da matéria seca alocou-se nos frutos, $19 \%$ nas folhas, $8 \%$ no caule, e o restante nas flores e raízes. Os nutrientes $\mathrm{N}, \mathrm{K}$, S e Cu acumularam-se preferencialmente nos frutos, enquanto o $\mathrm{P}, \mathrm{Ca}, \mathrm{Mg}, \mathrm{Zn}, \mathrm{Fe}$ e $\mathrm{Mn}$ na parte vegetativa. Os frutos exportaram $51,0 \mathrm{~kg} \mathrm{ha}^{-1} \mathrm{de} \mathrm{N} ; 12,4 \mathrm{~kg} \mathrm{ha}^{-1} \mathrm{de}$ P; 61,4 kg ha-1 de K; 3,6 kg ha-1 de S; 8,8 kg ha-1 de Ca e 3,5 kg ha-1 de Mg, e 11,4 g ha ${ }^{-1}$ de Cu; 61,6 g ha ${ }^{-1}$ de Zn; 126,6 g ha ${ }^{-1}$ de Fe e 44,3 $\mathrm{g} \mathrm{ha}^{-1}$ de $\mathrm{Mn}$.

Palavras-chave: C. maxima x C. moschata, Tetsukabuto, análise do crescimento, nutrição macro e micronutrientes.

\begin{abstract}
Growth and accumulation of nutrients in hybrid squash Tetsukabuto

An experiment was carried out at Jaíba, Northern Minas Gerais State, to evaluate the growth and accumulation of nutrients in hybrid squash cv. Suprema. The samplings of plants were taken at 28; 42; 56; 70; 84, and 98 days after the sowing (DAS) for dry matter determination of leaves, stem, flower, fruit and root. The plants grew slowly up the 56 DAS, intensifying thereon. The total production of maximum dry matter occurred at 89 DAS, reaching 1657.92 g plant ${ }^{1}$. The fruits accumulated more dry matter than the other organs of the plant. The rate of absolute growth of plants and fruits were 124.25 and 172.75 g plant $^{-1}$ day $^{-1}$, at 74 days and 79 days, respectively. The nutrient absorption patterns followed the plant dry matter accumulation. The accumulation of nutrients was low in the first 42 days, intensifying thereon for $\mathrm{N}, \mathrm{S}, \mathrm{Mg}$, and the micronutrients. $\mathrm{K}$ was the nutrient more absorbed by the plant, followed by $\mathrm{N}$ and $\mathrm{Ca}$. The order of accumulation of nutrients was $\mathrm{K}>\mathrm{N}>\mathrm{Ca}>\mathrm{P}>\mathrm{Mg}>\mathrm{S}$ and $\mathrm{Fe}>\mathrm{Mn}>\mathrm{Zn}>\mathrm{Cu}$. In the crop, at 98 days, $69 \%$ of the dry matter was allocated in the fruits, $19 \%$ in the leaves, $8 \%$ in the stem, and the remaining in the flowers and roots. The nutrients $\mathrm{N}, \mathrm{K}, \mathrm{S}$, and $\mathrm{Cu}$ accumulated in the fruits, while $\mathrm{P}, \mathrm{Ca}, \mathrm{Mg}, \mathrm{Zn}, \mathrm{Fe}$, and $\mathrm{Mn}$ accumulated in the vegetative part. The fruits exported $51.0 \mathrm{~kg} \mathrm{ha}^{-1}$ of N; $12.4 \mathrm{~kg} \mathrm{ha}^{-1}$ of P; $61.4 \mathrm{~kg} \mathrm{ha}^{-1}$ of K; $3.6 \mathrm{~kg} \mathrm{ha}^{-1}$ of S; $8.8 \mathrm{~kg} \mathrm{ha}$ ${ }^{1}$ of Ca and $3.5 \mathrm{~kg} \mathrm{ha}^{-1}$ of Mg, and $11.4 \mathrm{~g} \mathrm{ha}^{-1}$ of Cu; $61.6 \mathrm{~g} \mathrm{ha}^{-1}$ of Zn; $126.6 \mathrm{~g} \mathrm{ha}^{-1}$ of Fe and $44.3 \mathrm{~g} \mathrm{ha}^{-1}$ of Mn.
\end{abstract}

Keywords: C. maxima x C. moschata, Tetsukabuto, growth analysis, nutrition, macronutrients, micronutrients.

\section{(Recebido para publicação em 12 de abril de 2006; aceito em 6 de julho de 2007)}

$\mathrm{O}$ Norte de Minas Gerais, devido às condições edafoclimáticas favoráveis, apresenta grande potencial para a produção de cucurbitáceas e outras hortaliças. A produção da abóbora híbrida tipo Tetsukabuto tem-se destacado na região. Identificar o comportamento de crescimento de hortaliças na região, a partir de mensuração da matéria seca acumulada pela planta e, ou de suas partes secas (folhas, caule, frutos, flores e raizes) é fundamental ao planejamento do métodos de cultivo que expresse o máximo potencial produtivo das plantas.

A composição mineral ou o teor dos nutrientes nos tecidos foliares depende de fatores como planta (espécie, variedade, tipo de folha, idade etc.), solo, fertilizantes, clima, práticas culturais, pragas e doenças (Malavolta et al., 1997). De modo geral, a absorção de nutrientes em hortaliças segue o padrão da curva de crescimento (acúmulo de matéria seca). Entre os macronutrientes, o potássio é comumente o nutriente mais absorvido pelas hortaliças (Ferreira et al., 1993).

A marcha de absorção expressa na forma de curvas de resposta em função da idade das plantas, informa épocas em que essas absorvem os nutrientes em maiores quantidades, aumentando, assim, o conhecimento de épocas em que a adição de nutrientes às plantas faz-se necessário. Por isso, ela constitui ferramenta importantíssima ao manejo de fertilizantes das cultu- ras. No entanto, no Brasil, informações sobre a absorção de nutrientes pela cultura da abóbora híbrida, tipo Tetsukabuto, são escassas, e também na literatura estrangeira poucos trabalhos contemplam esta planta (Fontes \& Lima, 1993).

O presente trabalho objetivou determinar os acúmulos de matéria seca e de nutrientes pela abóbora híbrida, tipo Tetsukabuto, durante o seu ciclo de desenvolvimento na região Norte de Minas Gerais.

\section{MATERIAL E MÉTODOS}

Numa área de 0,5 ha, cultivada com abóbora híbrida utilizando o manejo de 


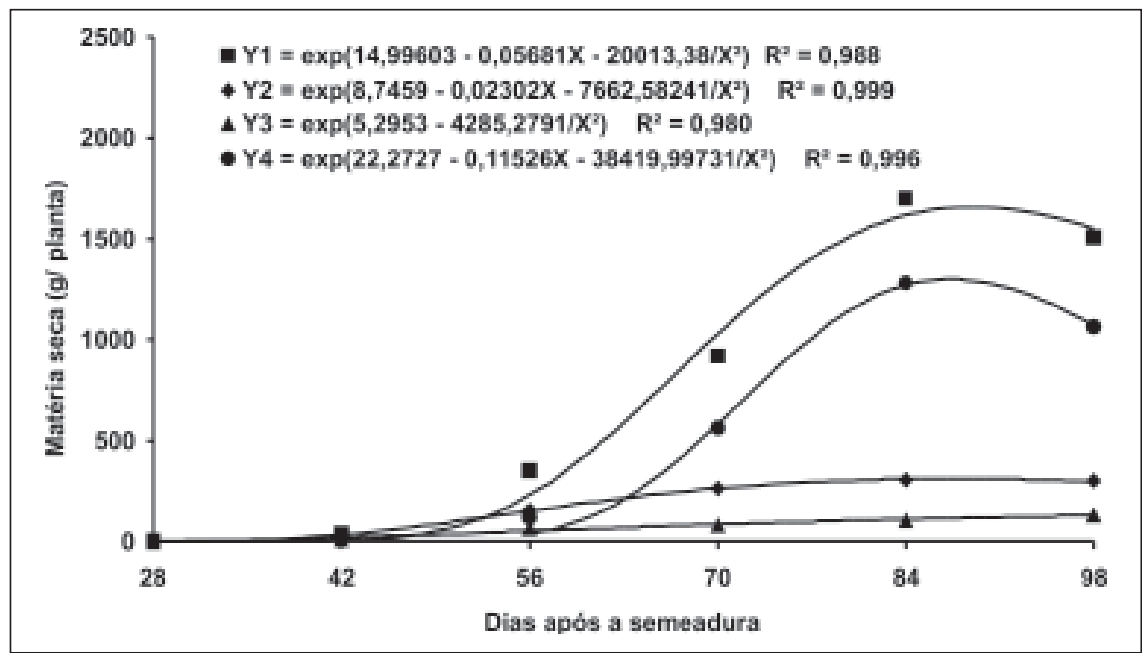

Figura 1. Acúmulo de matéria seca na planta (Y1), caule (Y2), folha (Y3) e fruto (Y4) pela cultura da abóbora híbrida cv. Suprema em Neossolo Quartzarênico na região Norte de Minas Gerais (accumulation of dry matter in the plant (Y1), stem (Y2), leaf (Y3) and fruit (Y4) of the hybrid squash cv. Suprema in a Quartzarenic Neossol in the northern region of Minas Gerais State). Jaíba, EPAMIG, 2002.

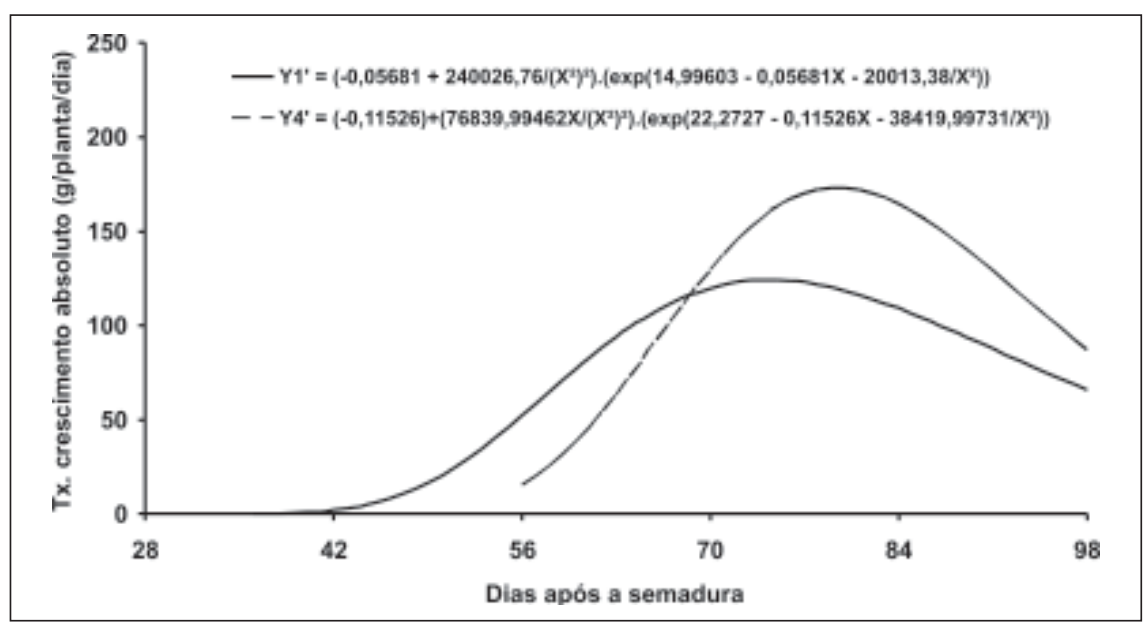

Figura 2. Taxa de crescimento absoluto da planta (Y1') e de frutos (Y4') da abóbora híbrida cv. Suprema em Neossolo Quartzarênico na região Norte de Minas Gerais (absolute growth rate of the plant (Y1') and fruits (Y4') of the hybrid squash cv. Suprema in a Quartzarenic Neossol in the northern region of Minas Gerais State). Jaíba, EPAMIG, 2002.

adubação dos produtores da região foi conduzido um experimento para avaliar o crescimento de abóbora híbrida, em área da EPAMIG, localizada dentro do Projeto Jaíba, região Norte de Minas Gerais, de abril a agosto de 2002. O solo da área, classificado como Neossolo Quartzarênico, apresentou a composição granulométrica: $130 \mathrm{~g} \mathrm{~kg}^{-1}$ argila; $50 \mathrm{~g}$ $\mathrm{kg}^{-1}$ silte e $820 \mathrm{~g} \mathrm{~kg}^{-1}$ areia; e química: $\mathrm{pH}$ (água) 5,8; Ca, $\mathrm{Mg}, \mathrm{Al}$ e $\mathrm{H}+\mathrm{Al}$ respectivamente 21,$0 ; 2,5 ; 0,0$ e $9,0 \mathrm{mmol}$ $\mathrm{dm}^{-3}$; P e K, 70,65 e 44,00 $\mathrm{mg} \mathrm{dm}^{-3}$; e matéria orgânica $=5,90 \mathrm{~g} \mathrm{dm}^{-3}$. As análises químicas foram realizadas de acor- do com metodologias descritas por Raij et al (2001).

Em maio de 2002, aos 15 dias após a semeadura (DAS), as mudas de abóbora híbrida cv Suprema foram transplantadas para covas, espaçadas de 3,0 x $1,5 \mathrm{~m}$, e previamente adubadas com 2,0 L de esterco de gado, $200 \mathrm{~g}$ de adubo formulado 4-30-10 e 10 g de bórax. Na adubação de cobertura, parcelou-se o N em três vezes (27; 43 e 64 DAS) e o $\mathrm{K}$ em duas (43 e 64 DAS), aplicando-se 10; 50 e 40 g planta $^{-1}$ de uréia; e 30 e 30 g planta ${ }^{-1}$ de cloreto de potássio. No início da floração e da frutificação, aplicou- se o adubo foliar $\mathrm{CaB}_{2}$ Plus na dose de 3,0 L ha-1. A cultura foi conduzida com irrigação por aspersão convencional.

Durante o cultivo foram retiradas amostras compostas por nove plantas em seis épocas distintas. Iniciou-se a coleta de amostras desde 28 DAS até a colheita final, considerando um intervalo regular de 14 dias. O material amostrado foi separado em folha, caule, raiz, flor e fruto, secado em estufa de circulação forçada de ar a $65^{\circ} \mathrm{C}$ até peso constante, obtendo-se, assim, o acúmulo de matéria seca na abóbora. Esses dados associados às épocas de coleta das amostras foram usados para determinar a curva de acúmulo de matéria seca pela abóbora híbrida.

Os dados de matéria seca foram submetidos à análise de regressão, tendo como variável independente a idade da planta, expressa em dias após a semeadura. O crescimento das plantas foi caracterizado pela produção de matéria seca das folhas, caule, flor, fruto e raiz, e a taxa de crescimento absoluto da planta e do fruto por meio da derivada primeira da equação ajustada à massa da matéria seca da planta e do fruto, respectivamente.

As amostras foram moídas em moinho tipo Wiley e analisadas para determinação dos teores de N, P, K, S, Ca, $\mathrm{Mg}, \mathrm{Zn}, \mathrm{Cu}, \mathrm{Mn}$ e Fe. Esses dados associados às épocas de coleta das amostras foram usados para determinar a curva de absorção de nutrientes pela abóbora híbrida.

Os dados sobre a absorção de nutrientes foram submetidos à análise de regressão, tendo como variável independente a idade da planta, expressa em dias após a semeadura. A taxa diária de absorção de nutrientes pela planta e a taxa diária de alocação de nutrientes no fruto foram estimadas, por meio da derivada primeira da equação ajustada para a absorção de cada nutriente pela planta e fruto, respectivamente.

\section{RESULTADOS E DISCUSSÃO}

A planta de abóbora híbrida tipo Tetsukabuto, cv. Suprema, teve lento crescimento até 56 DAS, intensificando-se a partir daí a produção de matéria seca até o final do ciclo. Houve acúmulo 
de matéria seca das plantas, ao longo do ciclo, sendo que a produção total de matéria seca máxima ocorreu aos 89 DAS, atingindo $1.657,92$ g planta $^{-1}(\mathrm{Fi}-$ gura 1). No período de 56 a 84 DAS, a taxa de crescimento absoluto da planta (G) acelerou, atingindo valor máximo, de 124,21 g planta $^{-1} \cdot$ dia $^{-1}$, aos 74 DAS (Figura 2).

As folhas acumularam matéria seca lentamente até os 42 DAS quando, a partir de então, houve uma aceleração no acúmulo de matéria seca, atingindo aos 87 DAS, a quantidade máxima estimado em 308,21 g planta $^{-1}$. O caule acumulou matéria seca continuamente até a colheita, atingindo 127,62 g planta ${ }^{-1}$ aos 98 DAS

O acúmulo de matéria seca pelos frutos, determinado a partir dos 56 DAS, foi pequeno inicialmente, e teve seu crescimento acelerado no período de 63 a 84 DAS, quando atingiu a taxa de crescimento máxima de 172,70 g planta $^{-1}$ dia ${ }^{-1}$, aos 79 DAS (Figura 2). Entre os órgãos da planta, os frutos foram os que mais acumularam matéria seca, atingindo, aos 87 DAS, a quantidade máxima estimada em 1.298,69 g planta $^{-1}$ (Figura 1), demonstrando ser o dreno principal na partição de fotoassimilados, a exemplo do ocorrido com outras hortaliças fruto, como o tomate (Fayad et al., 2001) e melancia (Grangeiro \& Cecílio Filho, 2004, 2005).

As primeiras flores foram produzidas próximo aos 40 DAS, atingindo máximo acúmulo matéria seca de 5,43 g planta $^{-1}$ aos 65 DAS, período de plena floração e frutificação. As raízes, por sua vez, atingiram o máximo acúmulo de matéria seca aos 81 DAS, alcançando 11,69 g planta $^{-1}$, representando menos de $1 \%$ da matéria seca total da planta (dados não apresentados).

Até 56 DAS, o acúmulo de matéria seca na parte vegetativa das plantas representou cerca de $60 \%$ do total (Figura 1). Após isso, com a frutificação, alterou-se a força de drenos da planta, proporcionada pela predominância da fase reprodutiva sobre a vegetativa, aumentando a translocação de fotoassimilados das folhas para os frutos (Marschner, 1995).

A quantidade acumulada de nutrientes seguiu o padrão da curva de acúmulo

Tabela 1. Quantidade máxima de nutriente acumulado e taxa diária máxima de absorção e alocação na planta e nos frutos de abóbora híbrida, cv. Suprema (maximal quantity of nutrients accumulated, and maximal absorption and allocation quantity/day in plants and fruits of hybrid squash cv. Suprema). Jaíba, EPAMIG, 2002.

\begin{tabular}{lcrrr}
\hline Nutriente & $\begin{array}{c}\text { Acúmulo } \\
\text { máximo na } \\
\text { planta }^{1}\end{array}$ & $\begin{array}{c}\text { Acúmulo } \\
\text { máximo no } \\
\text { fruto }^{1}\end{array}$ & $\begin{array}{c}\text { Taxa máxima de } \\
\text { absorção da } \text { planta }^{2}\end{array}$ & $\begin{array}{c}\text { Taxa máxima de } \\
\text { alocação no }^{\text {fruto }}{ }^{2}\end{array}$ \\
\hline $\mathrm{N}$ & 30.200 & 22.973 & $1.046,29$ & $2.525,03$ \\
$\mathrm{P}$ & 8.483 & 5.592 & $1.031,43$ & 991,22 \\
$\mathrm{~K}$ & 35.554 & 27.657 & $1.673,43$ & $3.152,80$ \\
$\mathrm{~S}$ & 2.285 & 1.631 & 66,74 & 189,38 \\
$\mathrm{Ca}$ & 23.154 & 3.944 & 954,79 & 396,98 \\
$\mathrm{Mg}$ & 4.507 & 1.564 & 92,04 & 205,32 \\
$\mathrm{Cu}$ & 7.532 & 5.112 & 147,02 & 465,04 \\
$\mathrm{Zn}$ & 50.556 & 27.736 & $1.149,33$ & $3.709,09$ \\
$\mathrm{Fe}$ & 346.950 & 57.031 & $7.615,69$ & $18.143,41$ \\
$\mathrm{Mn}$ & 231.625 & 19.953 & $5.084,52$ & $2.356,62$ \\
\hline
\end{tabular}

${ }^{1} \mathrm{mg}_{\text {planta }}{ }^{-1}$ para os macro e $\mu$ g planta ${ }^{-1}$ para os micronutrientes; ${ }^{2} \mathrm{mg} \mathrm{planta}^{-1} \mathrm{dia}^{-1}$ para os macro e $\mu$ g planta ${ }^{-1} \mathrm{dia}^{-1}$ para os micronutrientes $\left({ }^{1} \mathrm{mg} \mathrm{plant}^{-1}\right.$ for the macro and $\mu \mathrm{g}$ plant ${ }^{-1}$ for the micronutrients; ${ }^{2} \mathrm{mg}_{\text {plant }}{ }^{-1} \mathrm{dia}^{-1}$ for the macro and $\mu \mathrm{g}$ plant ${ }^{-1}$ day $^{-1}$ for the micronutrients).

de matéria seca pelas plantas. O acúmulo de nutrientes foi reduzido nos primeiros 42 DAS, intensificando-se a partir daí, acumulando continuamente até o final do ciclo para $\mathrm{N}, \mathrm{S}, \mathrm{Mg}$ e os micronutrientes (Figuras 3 e 4). O K foi o nutriente absorvido em maior quantidade pela planta, seguido do $\mathrm{N}$ e $\mathrm{Ca}$, como tem sido verificado para a maioria das hortaliças, em que o K é o nutriente mais acumulado (Ferreira et al., 1993). Na seqüência, os macronutrientes acumulados em menor quantidade foram $\mathrm{P}, \mathrm{Mg}$ e $\mathrm{S}$, portanto a ordem de quantidades de macronutrientes acumulados foi $\mathrm{K}>\mathrm{N}>\mathrm{Ca}>\mathrm{P}>\mathrm{Mg}>\mathrm{S}$. Este comportamento tem sido verificado para outras cucurbitáceas como melão (Lima, 2001), pepino (Solis et al., 1988), abobrinha (Araújo et al., 2001) e melancia (Grangeiro \& Cecílio Filho, 2004, 2005).

A quantidade máxima de K acumulada foi estimada em 35.554 mg planta $^{-1}$, aos 88 DAS, sendo que a maior parte do $\mathrm{K}$ (87,63\%) foi acumulada no período de 49 a 77 DAS (Figura 3C e Tabela 1 e 2). As folhas, o caule e os frutos acumularam 25, 12 e $60 \%$ do total de K acumulado pela planta. Embora, o K não faça parte de um composto orgânico da planta, este desempenha diversas funções importantes, como na fotossíntese, síntese de proteínas e ativação enzimática, além do transporte de carboidratos (Taiz
\& Zeiger, 1991; Marschner, 1995). Neste caso, essa função de transporte de carboidratos explicaria o maior acúmulo nos frutos, como tem sido observado em outras hortaliças fruto (Solis et al., 1988; Lima, 2001; Araújo et al., 2001; Fayad et al., 2001; Grangeiro \& Cecílio Filho, 2004, 2005).

A quantidade de $\mathrm{N}$ acumulada foi estimada em $30.200 \mathrm{mg}$ planta $^{-1}$, aos 98 DAS, sendo que a maior parte do $\mathrm{N}$ (77,90\%) foi acumulada no período de 49 a 77 DAS (Figura 3A e Tabela 1 e 2), período de intenso acúmulo de matéria seca pela planta. As folhas, o caule e os frutos acumularam 25\%, $11 \%$ e $64 \%$ do total acumulado, respectivamente.

$\mathrm{O}$ acúmulo de $\mathrm{N}$ nas folhas foi reduzido até os 42 DAS, quando atingiu 1.889 mg planta ${ }^{-1}$, a partir de então o acúmulo foi intensificado alcançando o máximo estimado, aos 81 DAS, igual a $8.824 \mathrm{mg} \mathrm{planta}^{-1}$ (Figura 3A). No período de 42 a 77 DAS ocorreu o maior acúmulo de $\mathrm{N}$ nas folhas, representando cerca de $36 \%$ do total acumulado pela planta neste período. No caule, o acúmulo de $\mathrm{N}$ foi continuo, alcançando o valor estimado de 3.467 mg planta $^{-1}$ aos 98 DAS. Os frutos acumularam $\mathrm{N}$ dos 56 aos 87 DAS, quando o acúmulo máximo estimado foi igual a $22.973 \mathrm{mg}$ planta $^{-1}$ (Figura 3A e Tabela 1).

O cálcio atingiu quantidade máxima estimada em 23.154 mg planta $^{-1}$, aos 92 


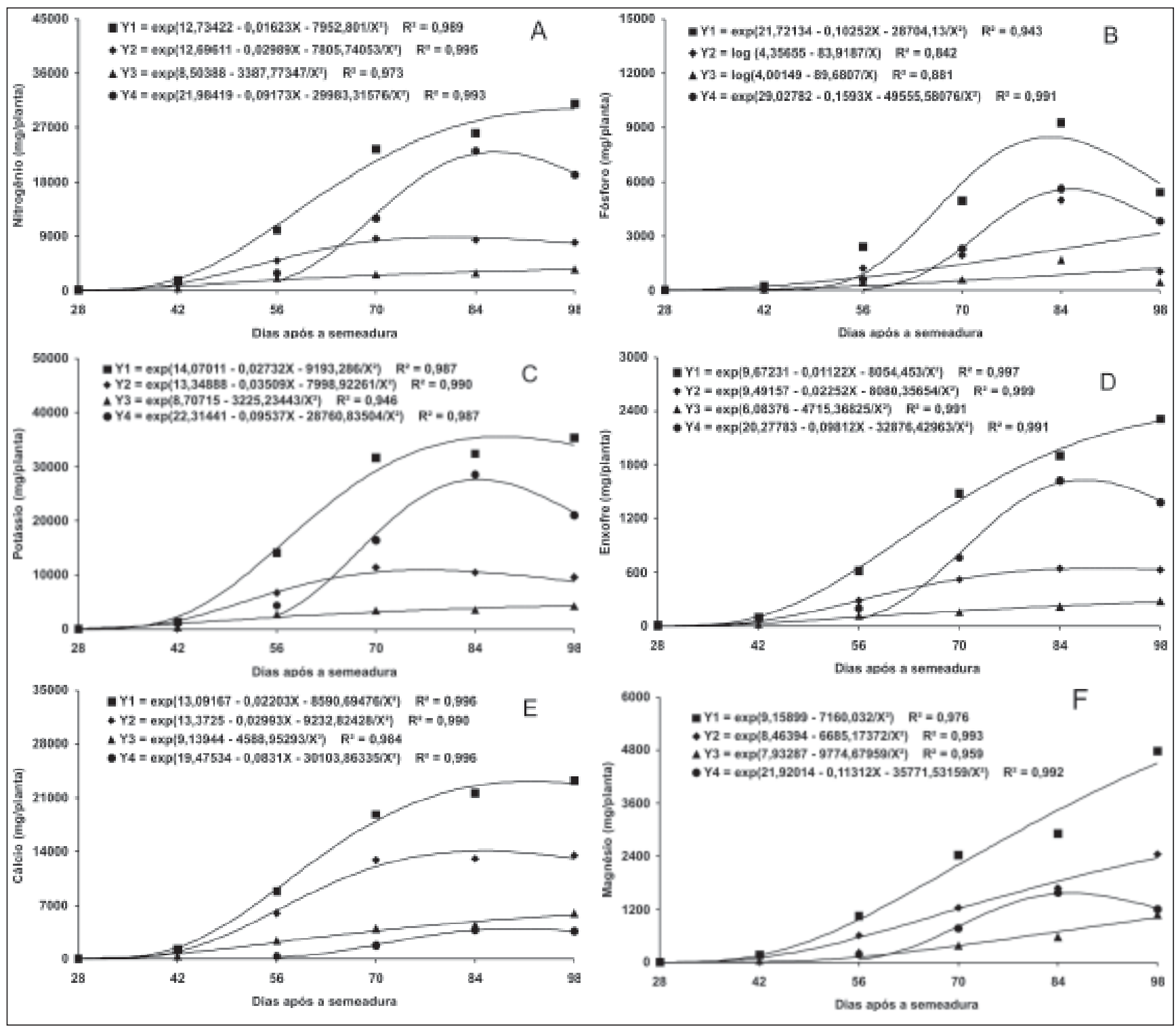

Figura 3. Acúmulo de nitrogênio (A), fósforo (B), potássio (C), enxofre (D), cálcio (E) e magnésio (F), em planta com raiz (Y1), folhas (Y2), caule (Y3) e frutos (Y4) de abóbora híbrida, cv. Suprema, cultivada na região Norte de Minas de Gerais, em função da idade (N accumulation (A), P (B), K (C), S (D), Ca (E) and Mg (F), in plants+roots (Y1), leaves (Y2), stem (Y3) and fruits (Y4) of hybrid squash, cv. Suprema in a Quartzarenic Neossol in the norther region of Minas Gerais State). Jaíba, EPAMIG, 2002.

DAS, sendo que a maior parte do $\mathrm{Ca}$ $(83,80 \%)$ foi acumulada no período de 49 a 77 DAS (Figura 3E e Tabela 1). Foi o macronutriente que mais acumulou nas folhas (56\%) e o caule e os frutos acumularam 25 e $16 \%$ do total de Ca acumulado pela planta, respectivamente. Esta distribuição do Ca se deve ao fato da sua movimentação na planta ocorrer, praticamente via xilema, por meio da corrente transpiratória, o que permite o maior acúmulo de Ca na parte vegetativa em relação aos frutos. Resultado similar foi observado para melancia (Grangeiro \& Cecílio Filho, 2004, 2005).
A planta acumulou fósforo lentamente até os 56 DAS, intensificando a partir de então e atingindo a quantidade máxima estimada de 8.483 mg planta $^{-1}$ aos 82 DAS. As folhas, caule e frutos acumularam 37; 14 e 45\%, respectivamente $\mathrm{O}$ período de maior acúmulo de P (98\%) foi de 56 a 84 DAS, coincidindo com o período de maior acúmulo de matéria seca de frutos, ou seja, período de formação dos frutos (Figura 3B e Tabela 1).

A planta acumulou $\mathrm{Mg}$ até o final do ciclo, atingindo o máximo estimado em 4.507 mg planta $^{-1}$, aos 98 DAS, sen- do que nos frutos o acúmulo máximo estimado em $1.564 \mathrm{mg}$ planta $^{-1}$, ocorreu aos 86 DAS. O período de maior acúmulo de Mg foi de 56 a 98 DAS, quando a planta acumulou cerca de 89,32\% do total. (Figura 3F e Tabela 1). De modo semelhante ao Ca, o magnésio foi acumulado em menor quantidade nos frutos (27\%) e maior quantidade na parte vegetativa, folhas e caule, 52 e $22 \%$, respectivamente, provavelmente por fazer parte da molécula de clorofila.

O macronutriente acumulado em menor quantidade foi o enxofre, com o máximo valor estimado de $2.285 \mathrm{mg}$ 

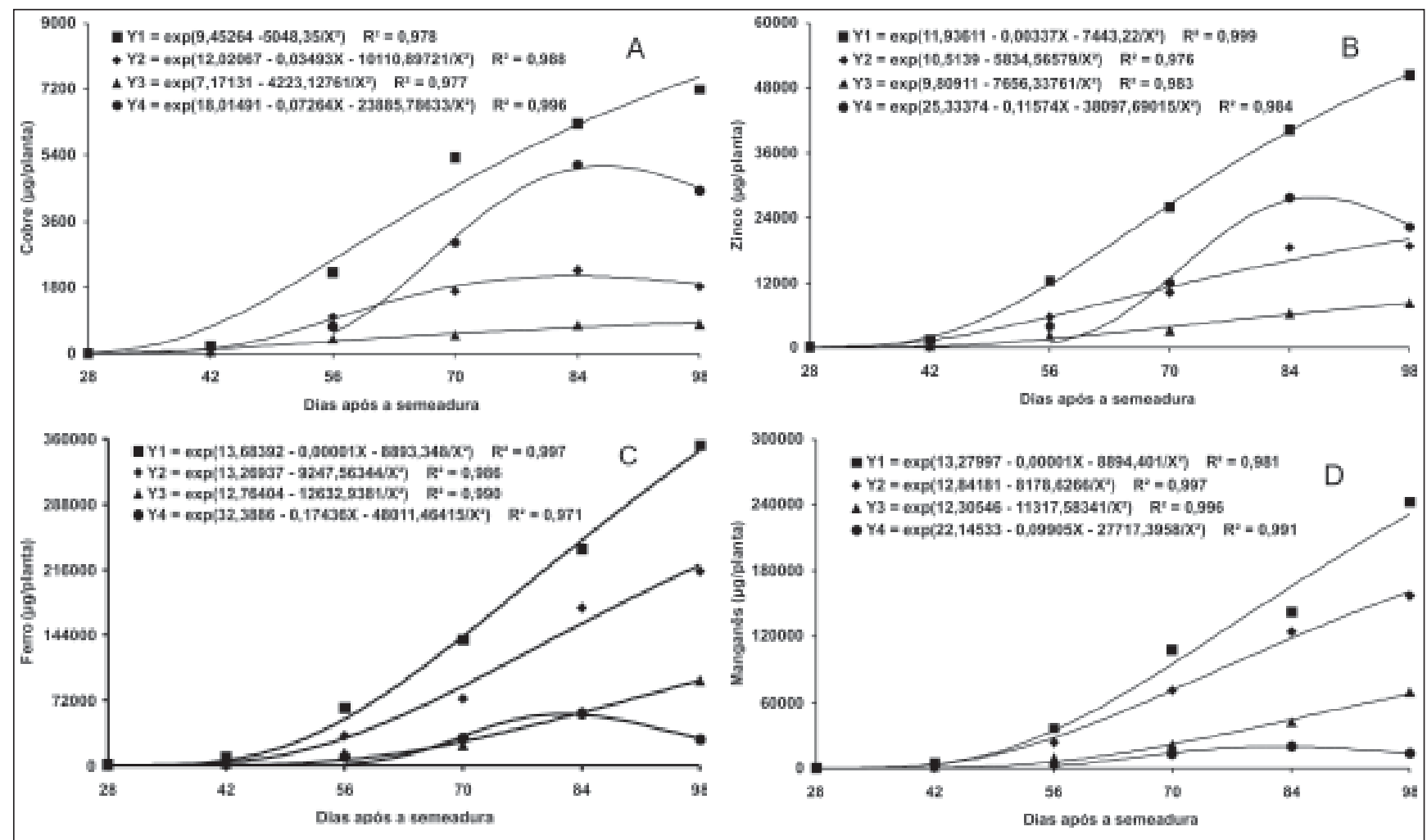

Figura 4. Acúmulo de cobre (A), zinco (B), ferro (C) e manganês (D), em planta com raiz (Y1), folhas (Y2), caule (Y3) e frutos (Y4) de abóbora híbrida , cv. Suprema, cultivada na região Norte de Minas de Gerais, em função da idade (accumulation of Cu (A), Zn (B), Fé (C) and Mn (D), in plants+roots (Y1), leaves (Y2), stem (Y3) and fruits (Y4) of hybrid squash cv. Suprema, cultivated in the northern region of Minas Gerais State, as a resulto f plant age). Jaíba, EPAMIG, 2002.

planta-1, ao final do ciclo, aos 98 DAS. O S acumulado distribuiu-se em 27, 12 e $61 \%$ nas folhas, caule e frutos, respectivamente. Nos frutos o acúmulo máximo estimado em 1.632 mg planta $^{-1}$, ocorreu aos 88 DAS. O período de maior acúmulo de S foi de 56 a 84 DAS, quando a planta acumulou próximo de $72,44 \%$ do total (Figura 3D e Tabela 1).

Os micronutrientes acumularam continuamente até o final do ciclo, sendo absorvidos na seguinte ordem decrescente: Fe, Mn, Zn e Cu (Figura 4 e Tabela 1). Entre os micronutrientes, o $\mathrm{Cu}$ (59\%) e o $\mathrm{Zn}(45 \%)$ foram os que mais acumularam nos frutos seguido do $\mathrm{Fe}$ (8\%) e Mn (6\%).

A taxa diária de absorção dos nutrientes pela abóbora híbrida foi crescente até os 63; 74; 63; 66; 63; 69; 58; 68; 77 e 77 DAS para N, P, K, S, Ca, $\mathrm{Mg}, \mathrm{Cu}, \mathrm{Zn}, \mathrm{Fe}$ e Mn, respectivamente (Figuras 3 e 4; Tabela 1). A máxima absorção diária de nutrientes ocorreu no período de plena frutificação. Atribuise maior absorção em tal época por ser um estádio de desenvolvimento de

Tabela 2. Quantidade relativa de N e K acumulada na planta inteira, em função da idade de abóbora híbrida tipo Tetsukabuto, cv. Suprema (relative quantity of $\mathrm{N}$ and $\mathrm{K}$ accumulated in the whole plant, depending on the age of the hybrid squash Tetsukabuto, cv. Suprema). Jaíba, EPAMIG, 2002.

\begin{tabular}{lcc}
\hline Idade da planta & \multicolumn{2}{c}{ Nutriente (\%) } \\
\hline (dias após a semeadura) & $\mathbf{N}$ & $\mathbf{K}$ \\
\hline 28 & 0,03 & 0,01 \\
35 & 0,94 & 0,75 \\
42 & 5,29 & 5,51 \\
49 & 12,21 & 14,39 \\
56 & 17,36 & 21,22 \\
63 & 18,63 & 22,12 \\
70 & 16,68 & 18,09 \\
77 & 13,02 & 11,81 \\
84 & 8,91 & 5,45 \\
91 & 5,08 & 0,65 \\
98 & 1,85 & - \\
\hline
\end{tabular}

acentuada demanda metabólica, associada à atividade hormonal e à divisão e crescimento das células (Taiz \& Zeiger, 1991).

Na colheita, aos 98 DAS, 69\% da matéria seca alocou-se nos frutos, 19\% nas folhas e $8 \%$ no caule, e o restante nas flores e raízes. Como os frutos acu- mularam 64\% do N, 45\% do P, 60\% do K, $16 \%$ do Ca, $22 \%$ do $\mathrm{Mg}, 61 \%$ do S, $59 \%$ do $\mathrm{Cu}, 45 \%$ do $\mathrm{Zn}, 8 \%$ do Fe e $6 \%$ do $\mathrm{Mn}$, portanto os nutrientes $\mathrm{N}, \mathrm{K}$, S e $\mathrm{Cu}$ acumulam-se preferencialmente nos frutos, enquanto o P, Ca, Mg, Zn, Fe e $\mathrm{Mn}$ na parte vegetativa. 
Os nutrientes mais acumulados pela abóbora híbrida, N e K, usualmente são aplicados em cobertura de forma parcelada. Pelos resultados, $\mathrm{N}$ e K foram absorvidos principalmente de 49 a 77 dias, o que demonstra a necessidade de maior disponibilidade desses nutrientes nessas épocas (Tabela 2). Essas necessidades de N e K, em função da idade da planta, foram obtidas a partir da equação da taxa diária de absorção, sendo ferramenta de fundamental importância na definição das quantidades e épocas de aplicação dos nutrientes em cobertura.

Considerando-se, uma população de plantas igual a 2.222 planta ha ${ }^{-1}$, as quantidades totais estimadas de $\mathrm{N}, \mathrm{P}, \mathrm{K}, \mathrm{S}$, $\mathrm{Ca}$ e $\mathrm{Mg}$ exportadas pelos frutos foram 51,0; 12,4; 61,4; 3,6; 8,8 e 3,5 kg ha-1, respectivamente, e ainda, exportaram 11,4; 61,6; 126,6 e 44,3 g.ha-1 de $\mathrm{Cu}$, Zn, Fe e Mn, respectivamente. Portanto, a quantidade de nutrientes exportados é um componente importante, devendo ser considerado na hora de definir o manejo da adubação para reposição de nutrientes.

\section{AGRADECIMENTOS}

À Fundação de Amparo à Pesquisa do Estado de Minas Gerais (FAPEMIG).

\section{REFERÊNCIAS}

ARAÚJO WF; BOTREL TA; CARMELLO QAC; SAMPAIO RA; VASCONCELOS MRB. 2001. Marcha de absorção de nutrientes pela cultura da abobrinha conduzida sob fertirrigação. In: FOLEGATTI MV; CASARINI E; BLANCO FF; BRASIL RPC; RESENDE RS (Coord.) Fertirrigação: flores, frutas e hortaliças. Guaíba: Agropecuária, v.1, p.67-77.

FAYAD JA; FONTES PCR; CARDOSO AA; FINGER LF; FERREIRA FA. 2001. Crescimento e produção do tomateiro cultivado sob condições de campo e de ambiente protegido. Horticultura brasileira 19: 365-370.

FERREIRA ME; CASTELLANE PD; CRUZ MCP. 1993. Nutrição e adubação de hortaliças. Simpósio sobre nutrição e adubação de hortaliças, Jaboticabal-SP, 1990. Potafós. 480p.

FONTES RR; LIMA JA. 1993. Nutrição mineral e adubação do pepino e da abóbora. In: FERREIRA ME; CASTELLANE PD; CRUZ MCP. Nutrição e adubação de hortaliças. Simpósio sobre nutrição e adubação de hortaliças, Jaboticabal-SP: Potafós. p.281-300.
GRANGEIRO LC; CECÍLIO FILHO AB. 2004. Acúmulo e exportação de macronutrientes pelo híbrido de melancia Tide. Horticultura brasileira 22: 93-97.

GRANGEIRO LC; CECÍLIO FILHO AB. 2005. Acúmulo e exportação de macronutrientes em melancia sem sementes. Horticultura brasileira 23: 763-767.

LIMA AA. 2001. Absorção e eficiência de utilização de nutrientes por híbridos de melão (Cucumis melo L.). Fortaleza: Universidade Federal do Ceará. 60p (Tese mestrado).

MAKISHIMA N. 1991. Situação das cucurbitáceas no Brasil. Horticultura brasileira 9: 99-101.

MALAVOLTA E; VITTI GC; OLIVEIRA SA 1997. Avaliação do estado nutricional das plantas. Piracicaba, Potafós. 319p.

MARSCHNER H. Mineral nutrition of higher plants. San Diego: Academic Press. 889p.

RAIJ B; ANDRADE JC; CANTARELLA H; QUAGGIO JA. 2001. Análise química para avaliação da fertilidade de solos tropicais. Campinas, Secretaria de Agricultura e Abastecimento, APTA e IAC. 284p.

SOLIS FAM; HAAG HP; MINAMI K; DIEHL WJ. 1988. Nutrição de hortaliças. LVI Acumulação de nutrientes na cultura do pepino (Cucumis sativus L.) var. Aodai cultivado em condições de campo. Anais da Escola Superior de Agricultura Luiz de Queiroz 39: 697737.

TAIZ L; ZEIGER E. 1991. Plant Physiology. Califórnia: Redwood City, The BenjaminCummings Publishing Company, 559p. 